\title{
Study on the Vibration of Slab Mill Based on Muti-body Dynamics
}

\author{
Zhao-wei Dong ${ }^{1, a}$ Xiao-hang Wan ${ }^{2, b}$ Sheng-yong Liu ${ }^{3, c}$ \\ ${ }^{1}$ Hebei University of Economics and Business, Shijiazhuang ,050061,China \\ ${ }^{2}$ Hebei College of Industry and Technology, 050091 Shijiazhuang Hebei, China \\ ${ }^{3}$ Hebei Normal University, 050031, Shijiazhuang Hebei, China \\ adong-zw@163.com, b81164095@qq.com, c sj7722@163.com
}

Keywords: Slab, Vibration Analysis, Mill, Muti-body dynamics.

Abstract:, The vibration analysis model of slab mill is established in this paper according with the multi-body dynamics theory. The relationship between the vibration displacement and time of the roller in different conditions is obtained through simulation analysis. Under different damping conditions, the vibration characteristics of the support roller is obtained, which can use in analyzing the mechanism and vibration reasons of the vibration of rolling mill. The results of the research can improve the quality of the products.

\section{Introduction}

The plate products are widely used in many fields, such as ship, bridge, container, and so on, especially raw material used as a production aircraft carriers, large ships and large diameter longitudinal welded pipe, which relates to energy security ${ }^{[1]}$. In the process of rolling production, the vibration of rolling mill is widely phenomenon ${ }^{[2]}$. The vibration of the rolling mill can easily speed up the wearing of the equipment, reduce the quality and output of the product, and greatly reduce the economic benefit of the enterprise ${ }^{[3]}$. The phenomenon of vibration caused by rolling mill is paid more and more attention, and it becomes an urgent problem to be solved ${ }^{[4]}$. The vibration analysis model of plate mill is established based on the multi-body dynamics theory. Through simulation analysis, the relationship between the vibration displacement and time of the work roller and the support roller in different conditions is obtained.

\section{The Analysis Model Process}

A 3D assembly model of the rolling mill is established by using 3D modeling software PROE. As shown in Figure 1. 

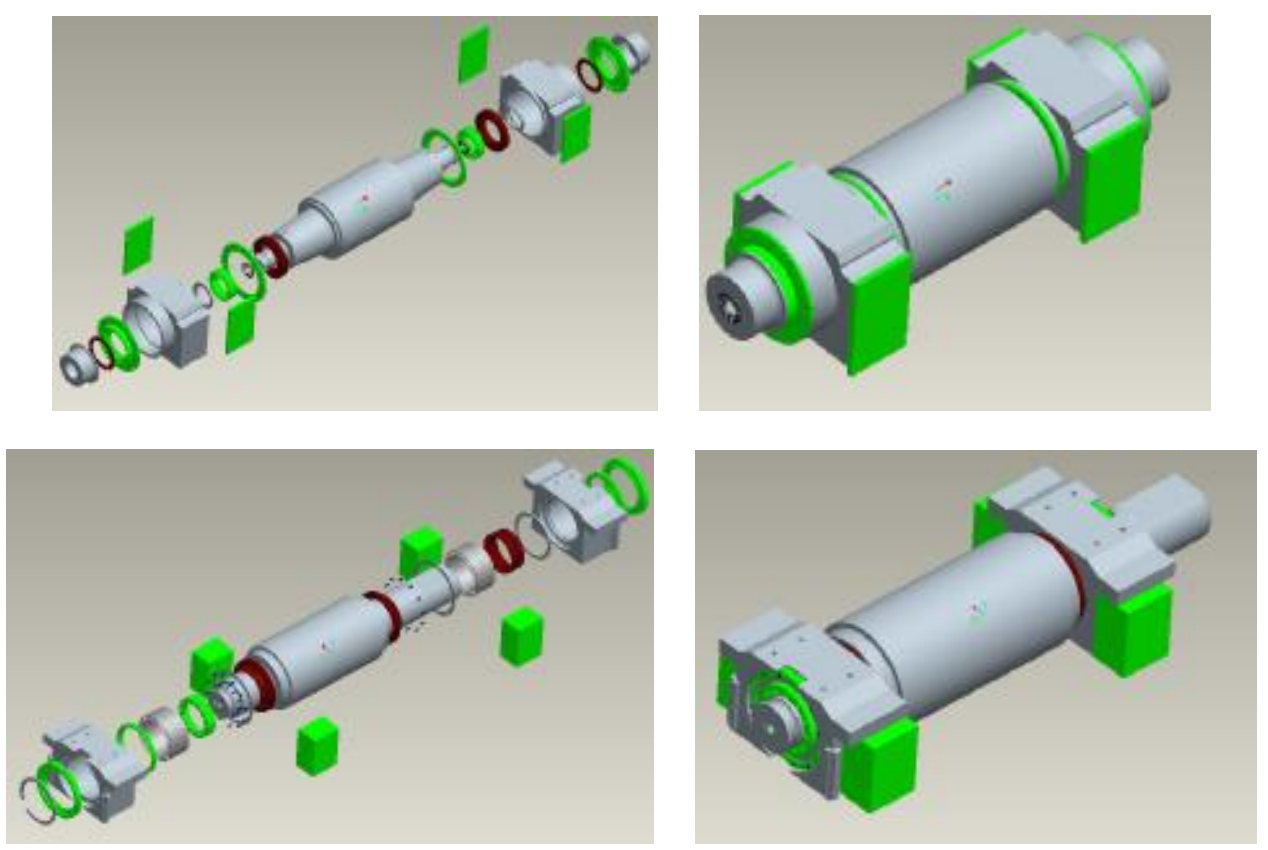

Fig1 roller model

Then, according to the assembly relationship, establish the model of the whole machine. As shown in Figure 2.

This model is imported into the ADAMS software, as shown in Figure 3.

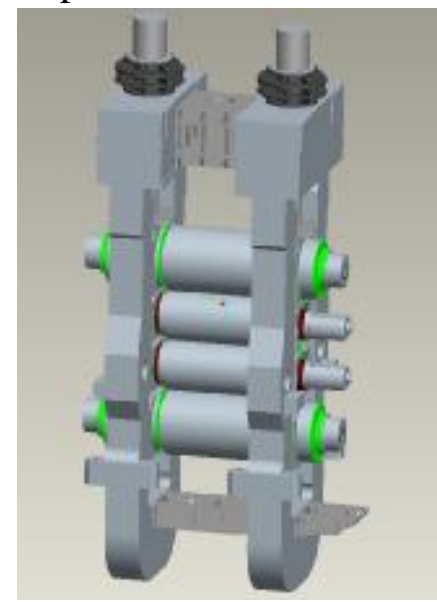

Fig2 whole model

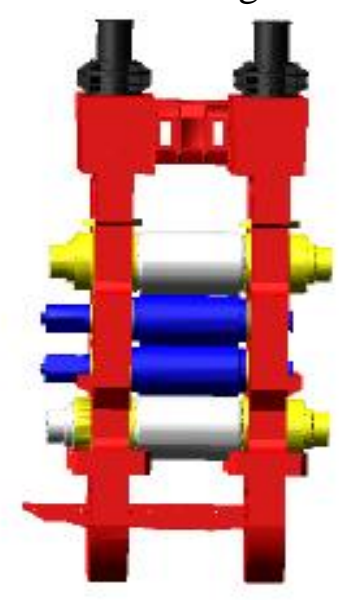

Fig3imported model

In order to facilitate the study, the relevant parts can be integrated into one. Then after, the summation of the model is to determine the centroid, definition of material, set the acceleration of gravity, measurement units, create grid working. The analysis model of rolling mill vibration simulation is established. According to its actual working state, the constraints and drive of the rolling mill model are applied. In the actual rolling process, the low frequency and vertical vibration of the rolling mill are mainly caused by damping. While the damping is caused by the friction between the bearing seat and the frame, and between the piston and the cylinder wall in the hydraulic system, which is determined flexible constraint type. As shown in Figure 4. 

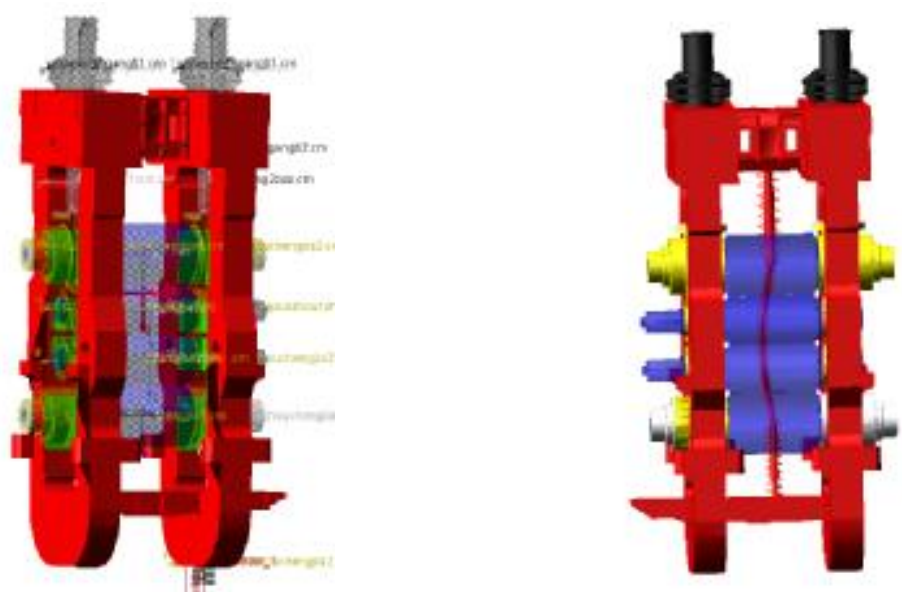

Fig4 the analysis model

\section{Result Analysis}

The source of vertical vibration mill confirmed firstly occurs in the roll gap. When the vertical vibration model is set up, the center of the strip at the roll gap is loaded. Because of the actual rolling process, the low frequency vertical vibration of rolling mill is caused by damping, and the damping of hydraulic system may be the main cause of low frequency vertical vibration. So it can study the influence of the damping of the hydraulic system on the low frequency vibration of the rolling mill. In order to facilitate the research, damping of the hydraulic system is simplified into two of the work rollers, which are connected by the spring, set up a spring model to simulate the damping of the hydraulic system.

In order to understand the effect of damping hydraulic cylinder on the vertical vibration of rolling mill system clearly and accurately, therefore three damping status are chosen in simulation process, for example, Damping conditions are $0 \mathrm{~N} / \mathrm{m} \bullet \mathrm{s}-1 、 1.5 \times 10^{7} \mathrm{~N} / \mathrm{m} \bullet \mathrm{s}-1 、 5 \times 10^{7} \mathrm{~N} / \mathrm{m} \bullet \mathrm{s}-1$ and the frequency response curve is obtained.

(1) Analysis of frequency response of upper support roller

Figure 5 to figure 7 for the frequency response curve of upper support roller in three under damping condition.

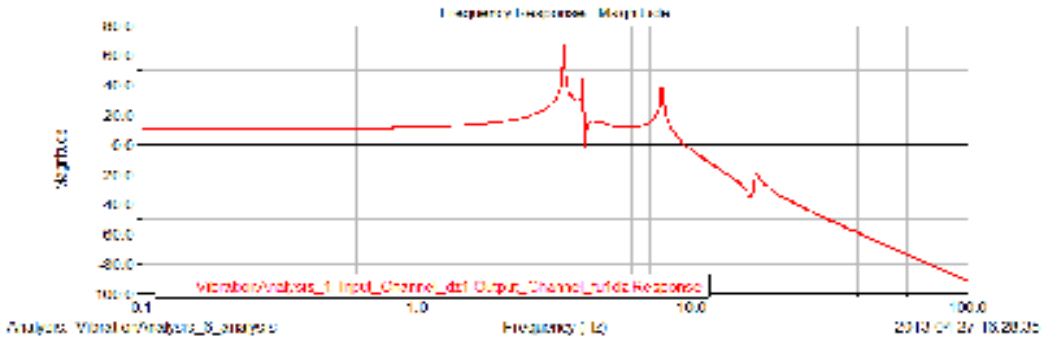

Fig5 damping condition $0 \mathrm{~N} / \mathrm{m} \bullet \mathrm{s}-1$ upper support roller response curve

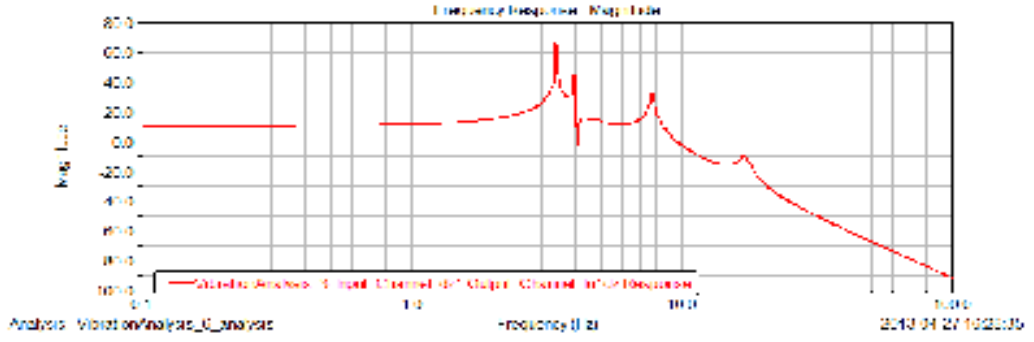

Fig6 damping condition $1.5 \times 10^{7} \mathrm{~N} / \mathrm{m} \bullet \mathrm{s}-1$ upper support roller response curve 


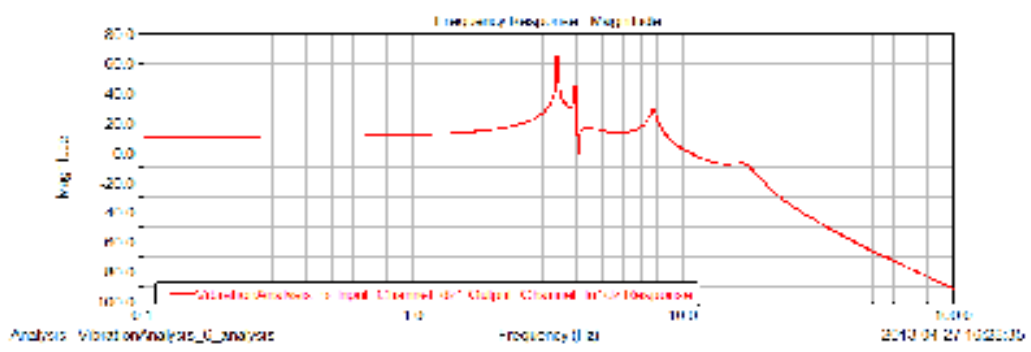

Fig7 damping condition $5 \times 10^{7} \mathrm{~N} / \mathrm{m} \bullet \mathrm{s}-1$ upper support roller response curve

From Figure 5 - Figure 7 shows, when the hydraulic system damping from 0 to $1.5 \times 10^{7} \mathrm{~N} / \mathrm{m}$ $\mathrm{s}-1$, the work and the maximum amplitude has no change. The maximum amplitude is 66 , and when the damping is increased in $10 \sim 100 \mathrm{~Hz}$, the vibration is obviously weakened.

(2) Analysis of frequency response of lower support roller

Figure 8 to figure 10 for the frequency response curve of lower support roller in three under damping condition.

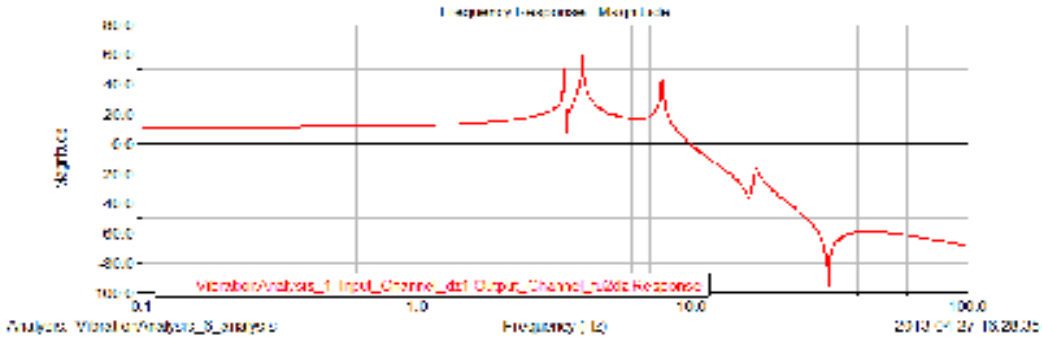

Fig8 damping condition $0 \mathrm{~N} / \mathrm{m} \bullet \mathrm{s}-1$ lower support roller response curve

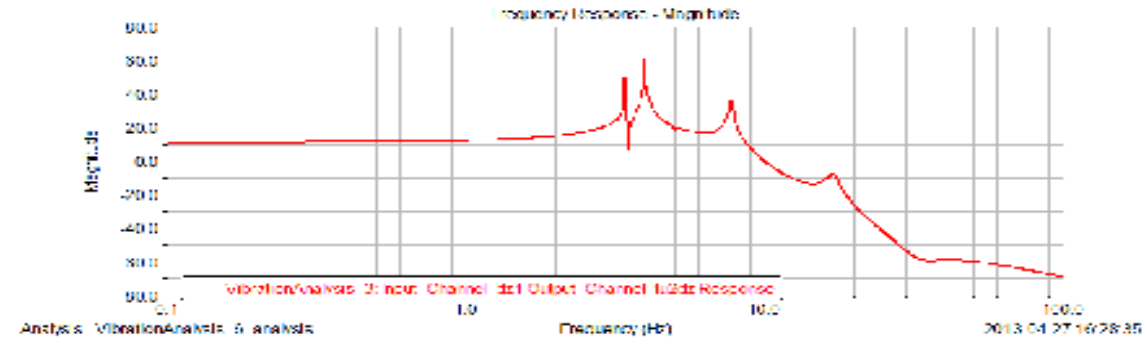

Fig9 damping condition $1.5 \times 10^{7} \mathrm{~N} / \mathrm{m} \bullet \mathrm{s}-1$ lower support roller response curve

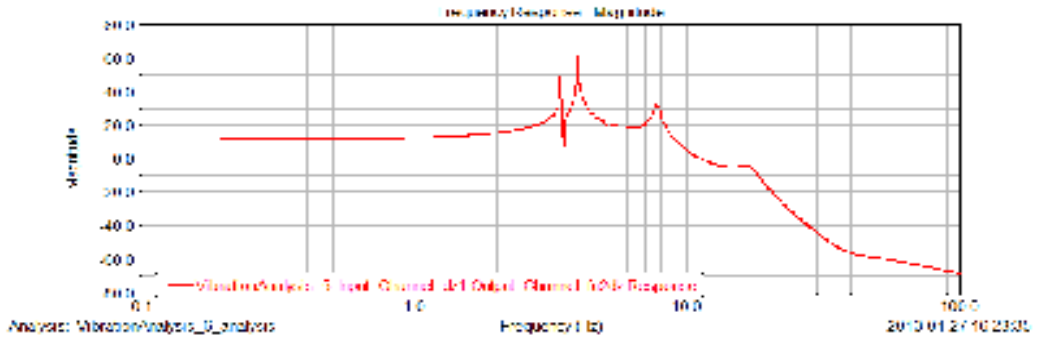

Fig10 damping condition $5 \times 10^{7} \mathrm{~N} / \mathrm{m} \bullet \mathrm{s}-1$ lower support roller response curve

By Figure 8 to figure 10 shows, when the hydraulic system damping from 0 to $1.5 \times 10^{7} \mathrm{~N} / \mathrm{m}$ $\mathrm{s}-1$, the work and the maximum amplitude is same with upper support roller. The maximum amplitude is 60 , and when the damping is increased in $10 \sim 100 \mathrm{~Hz}$, the vibration is obviously weakened too.

(3)Analysis of frequency response of upper working roller

Figure 11 to figure 13 for the frequency response curve of upper work roller in three under damping condition. 


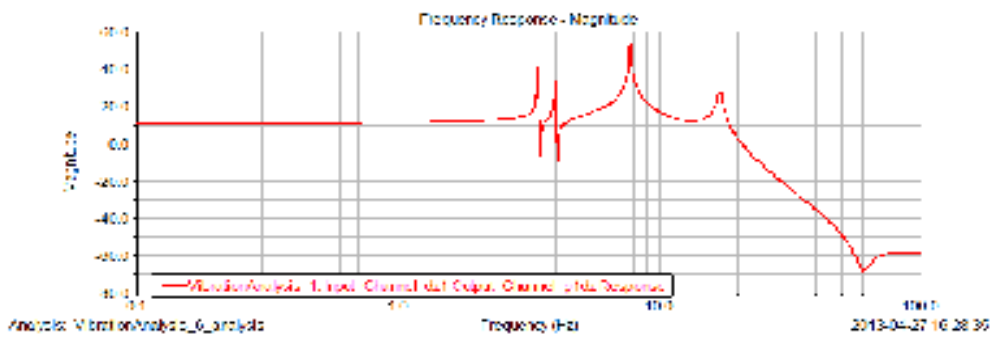

Fig11 damping condition $0 \mathrm{~N} / \mathrm{m} \bullet \mathrm{s}-1$ upper working roller response curve

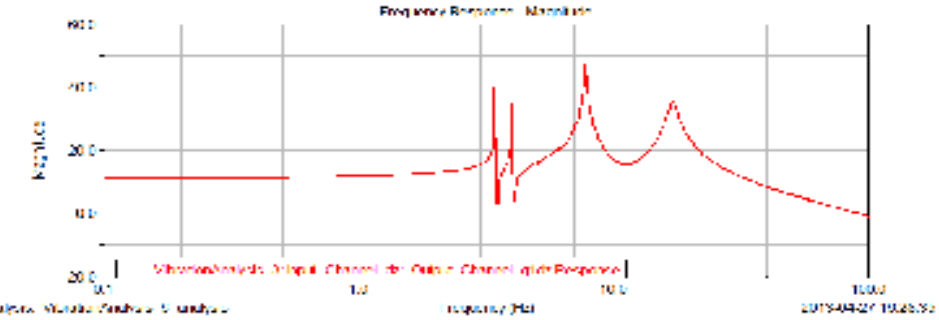

Fig 12 damping condition $1.5 \times 107 \mathrm{~N} / \mathrm{m} \bullet \mathrm{s}-1$ upper working roller response curve

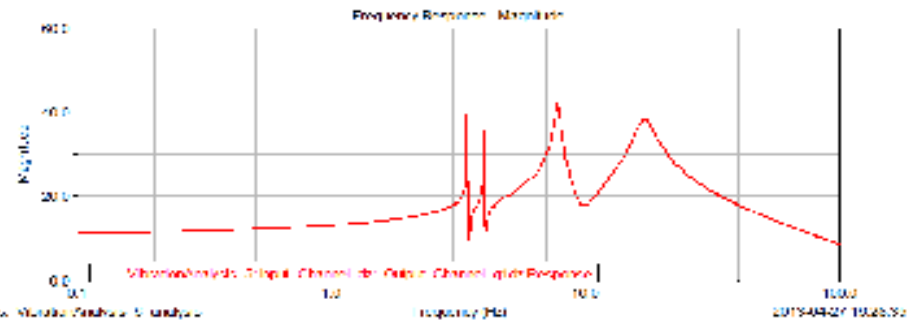

Fig 13 damping condition $5 \times 107 \mathrm{~N} / \mathrm{m} \bullet$ s-1 upper working roller response curve

From Figure 11 - Figure 13 shows, when the hydraulic system damping from 0 to $1.5 \mathrm{x}$ $107 \mathrm{~N} / \mathrm{m}-\mathrm{s}-1$, the work and the maximum amplitude by 55 down to 48 . The change of the amplitude of the 7 , and when the damping is increased to $5 \times 107 \mathrm{~N} / \mathrm{m}-\mathrm{s}-1$, the maximum amplitude was reduced from 48 to the 42 . The change of the amplitude of the 6 .

(4)Analysis of frequency response of lower working roller

Figure 14 to figure 16 for the frequency response curve of lower work roller in three under damping condition.

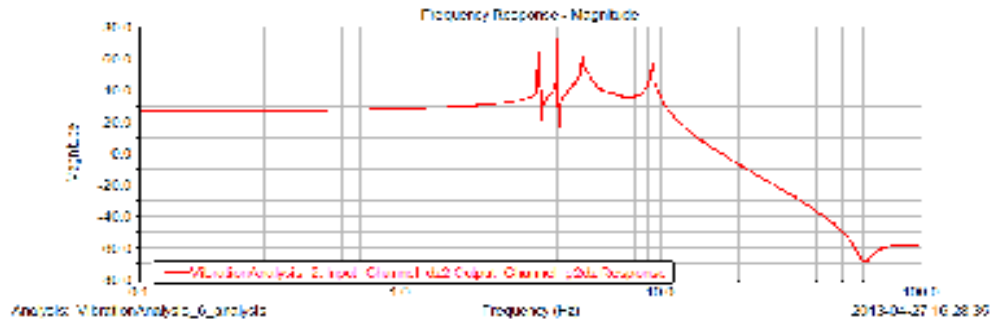

Fig 14 damping condition $0 \mathrm{~N} / \mathrm{m} \bullet \mathrm{s}-1$ lower work roller response curve

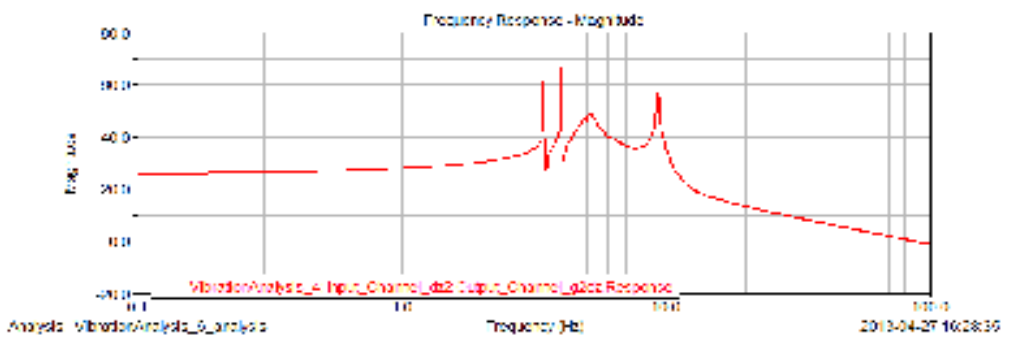

Fig15 damping condition $1.5 \times 107 \mathrm{~N} / \mathrm{m} \bullet \mathrm{s}-1$ lower work roller response curve 


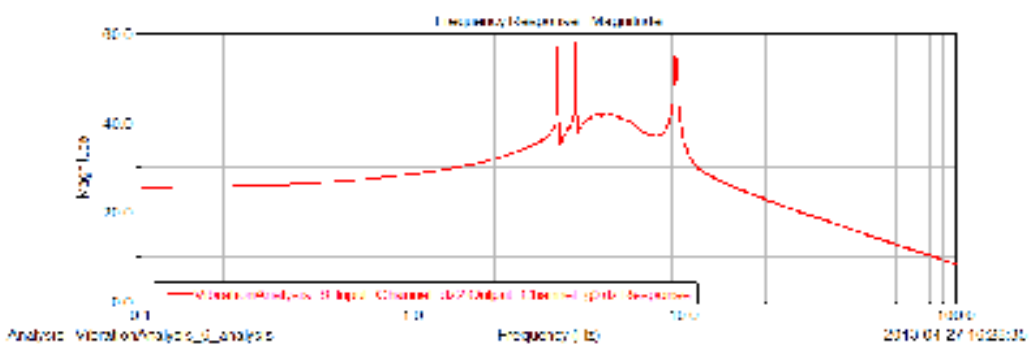

Fig16 damping condition $5 \times 107 \mathrm{~N} / \mathrm{m} \bullet \mathrm{s}-1$ lower work roller response curve

By Figure 14 to figure 16 shows, when the hydraulic system damping from 0 to $1.5 \mathrm{x}$ $107 \mathrm{~N} / \mathrm{m}-\mathrm{s}-1$, the work and the maximum amplitude by 74 reduced to 68 . The change of the amplitude of the 6 , and when the damping is increased to $5 \times 107 \mathrm{~N} / \mathrm{m}-\mathrm{s}-1$, the maximum amplitude was reduced from 68 to the 58 . The change of the amplitude of 10 .

\section{Conclusion}

The vibration of the rolling mill system is very intense at the low frequency, and the energy is relatively concentrated. The fluctuation of frequency band is also obvious in the $5-10 \mathrm{~Hz}$ system. According to the change of the amplitude analysis, the support roller vibration of the maximum amplitude variation of the average value is 0 , Thus when the damping is increased gradually, the vibration of upper and lower support roller have no change, which is benefit for reducing the whole vibration. Increasing the damp of the hydraulic system can greatly reduce, even avoid mill system of low-frequency vertical vibration. The work roller vibration of the maximum amplitude variation of the average value is 6 , the lower work roller is 8 . Thus when the damping is increased gradually, the vibration of upper and lower working roller significantly reduced, especially the lower work roller vibration, amplitude changes relatively large (average change 8), Increasing the damp of the hydraulic system can greatly reduce, even avoid mill system of low-frequency vertical vibration. It can be concluded from the spectrum that the amplitude of the vibration is gradually large and the divergence is the same.

\section{References:}

[1] MaoChengWang. The principle and numerical method of finite element method (the second edition)[M]. Tsinghua University press, 2002,494-496.

[2]Mohammad A, Younes M, Shahtout R, etal. A par ameters desig $n$ approach to improve product quality and equipment performance in hot rolling [J]. Journal of Materials Processing Technology, 2006, 171( 1) : 83-92.

[3] W.H. Sun, G.D. Wang, X.M. Zhang, etal. Analysis of work-piece cross section temperature field of the hot strip rolling process [J]. Journal of ShanDong Metallurgy, 1999,16 (4) :10 - 16.

[4] Witczak M, Obuchow icz A, Korb icz J Gene tic programming based approaches to identification and fault d iagnosis of nonlinear dynam ic System s [J]. Int J Control 2002,75 (13) : 1012-1031. 